\title{
Modeling, Prediction, and Control of Heating Temperature for Tube Billet
}

\author{
Yachun Mao, ${ }^{1}$ Dong Xiao, ${ }^{2}$ and Dapeng Niu ${ }^{2}$ \\ ${ }^{1}$ College of Resources and Civil Engineering, Northeastern University, Shenyang 110004, China \\ ${ }^{2}$ Information Science and Engineering School, Northeastern University, Shenyang 110004, China \\ Correspondence should be addressed to Dong Xiao; xiaodong@ise.neu.edu.cn
}

Received 26 May 2014; Revised 4 September 2014; Accepted 7 October 2014

Academic Editor: Yi Jin

Copyright (c) 2015 Yachun Mao et al. This is an open access article distributed under the Creative Commons Attribution License, which permits unrestricted use, distribution, and reproduction in any medium, provided the original work is properly cited.

\begin{abstract}
Annular furnaces have multivariate, nonlinear, large time lag, and cross coupling characteristics. The prediction and control of the exit temperature of a tube billet are important but difficult. We establish a prediction model for the final temperature of a tube billet through OS-ELM-DRPLS method. We address the complex production characteristics, integrate the advantages of PLS and ELM algorithms in establishing linear and nonlinear models, and consider model update and data lag. Based on the proposed model, we design a prediction control algorithm for tube billet temperature. The algorithm is validated using the practical production data of Baosteel Co., Ltd. Results show that the model achieves the precision required in industrial applications. The temperature of the tube billet can be controlled within the required temperature range through compensation control method.
\end{abstract}

\section{Introduction}

A seamless tube should be heated to a given temperature in an annular furnace prior to piercing. The heating quality of the tube billet directly influences the quality of the seamless tube. In seamless tube production, the main evaluation criterion for tube billet heating quality is the final exit temperature of the tube billet. The heating reaction mechanism of an annular furnace is complicated. It has nonlinear, large time lag, and uncertainty characteristics. The temperature distribution on the surface of a tube billet within the furnace cannot be directly measured and controlled [1]. Thus, controlling the outlet temperature of the billet is difficult.

Measuring the temperature of the billet in the furnace is also difficult. A common method is to establish a temperature prediction model for the billet. Several scholars have proposed mechanism models for billet temperature in furnaces. Chen et al. [2] established a temperature drop model of a tube billet during the transfer of the tube billet from the heating furnace to the rolling mill based on the partial differential equation of heating transfer. Jaklič et al. [3] established a mathematical model of deformation and heat flow during rough rolling. Considering that mechanism modeling is complex and modeling consumes much time, a model is usually established with a single furnace type and under many restricting conditions. Zhang et al. $[4,5]$ estimated the tube billet exit temperature through dynamic modeling of furnace temperature; however, the prediction error was too large to meet the requirements of the heating process. Wick [6] applied Kalman filter technique to estimate the temperature distribution of a tube billet inside a heating furnace. The disadvantage of this method is that the surface temperature of the tube billet inside the furnace must be measured, which is difficult to perform in practical production. Xiao et al. [7] employed production data and applied PCR method to establish a soft measurement model of tube billet temperature inside a furnace. However, this model has poor prediction precision because of the strong nonlinearity of production data. Chen and Chai [8] designed a preprocessing system for production process data. This system can predict several variables that are difficult to measure through the use of a selfadapting fuzzy-neural network. Cui and Ding [9] established a soft measurement model of tube billet temperature based on RBF neural network; however, model update was not considered. Iwamoto et al. [10] designed an automatic control system for a tube billet reheating rotary hearth furnace. 
The system consists of a component that calculates the tube billet temperature and a component that calculates the optimal furnace temperature set point. In large Chinese steel companies, such as Baosteel Co., Panzhihua Iron and Steel Co., Ltd., Anshan Iron and Steel Co., Ltd., and Capital Iron and Steel Co., Ltd., temperature prediction models are utilized in several heating furnaces. However, their prediction models are almost entirely engineering models imported from abroad. Therefore, these models are difficult to maintain and transplant, and the costs of doing so are high.

With the development of configuration software and database technique, increasing amounts of production data are being collected and stored. Therefore, data-driven modeling and control methods are eliciting more and more attention. He et al. [11] and Lv et al. [12] established data models for the Ladle furnace through data-driven methods. In the present work, the production data of an annular furnace were obtained from the seamless tube subcompany of Baosteel. Industrial process data contain noise, which reduces the modeling accuracy of the extreme learning machine (ELM) algorithm. By contrast, the capability of the partial least square (PLS) algorithm to process linear relevant data is suitable. Moreover, some cyclical changes occur in production. Thus, the model should be updated in real time. Online sequential (OS) ELM and recursive PLS algorithm can realize model update. Online sequential extreme learning machine dynamic recursive partial least square (OS-ELM-DRPLS) algorithm was proposed in this study. A tube billet temperature prediction model based on this algorithm was established, and a strategy for the optimization and control of tube billet temperature was proposed based on this model. OS-ELM-DRPLS not only has the advantages of the OS-ELM algorithm (e.g., rapid nonlinear modeling and update) but also has the capability of the RPLS algorithm to process linear relevant data. The large time lag and reduced model precision were solved through dynamic processing. The algorithm is easy to implement with advanced computer language. Configuration software, such as WINCC6.1, can be utilized to compile the modeling and control algorithms into special modules for use in industrial sites. Simulation and actual experiments prove that tube billet temperature can be predicted and controlled within the scope of the production process requirements with the established temperature prediction model and the proposed strategy of optimization and control based on OS-ELMDRPLS algorithm.

\section{Annular Furnace}

An annular furnace is a type of rotary hearth furnace utilized for tube billet heating. It consists of the furnace shaft and auxiliary equipment for charging and discharging. The furnace shaft consists of a fixed furnace roof, a ring-type tunnel surrounded by a fixed furnace roof wall, and a circular ring-like rotary hearth, as shown in Figure 1.

External and inner ring seams are placed between the fixed furnace wall and rotary hearth in an annular furnace. Internal and external water seal tanks are arranged

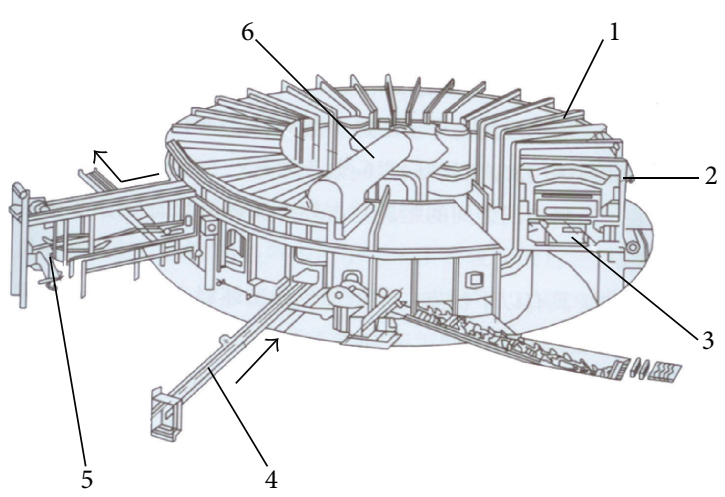
(1) Roof
(4) Charger
(2) Wall
(5) Discharger
(3) Rotary hearth
(6) Pipeline system

FIGURE 1: Schematic of annular furnace.

beneath the external and inner ring seams to maintain normal temperature and pressure in the furnace cavity and prevent external cold air from entering the furnace cavity. Fuel gas and combustion-supporting air are blown into the furnace through burning nozzles mounted on the external and internal walls or furnace roof to make the gas burn within the furnace and heat the tube billet. The fumes produced by gas burning within the furnace move conversely through the rotary hearth to the tail end of the soaking zone, enter the flue and chimney outside the furnace, and exit to the atmosphere. The external wall of the furnace has charging and discharging furnace doors, in which a charger and discharger are placed, respectively. Charging and discharging proceed simultaneously. When a tube billet is placed in the furnace, the bottom rotates at a certain angle. Tube billets follow a radial layout inside the furnace and are arranged either in a single row or in multirows.

The furnace cavity is divided into preheating, heating, and soaking zones according to the heating process of the tube billet in the annular furnace. Burning nozzles are not mounted in the preheating zone. A flue opening is arranged on the side wall near the charging furnace door in this zone. Hightemperature exhaust gas flows toward the opposite direction of hearth rotation and exits into the atmosphere through the flue opening in the heating and soaking zones. During the flow process of high-temperature exhaust gas, the tube billets in the preheating zone are mainly convection heated. The length of the preheating zone accounts for approximately one-fourth of the peripheral length of the annular furnace. Temperature differences between the surface and center and between both ends exist in the tube billet rapidly heated in the heating zone. To reduce the temperature difference of the tube billets and eliminate their male-female faces, the tube billets must be heated in the soaking zone. The length of the soaking zone is approximately three-twentieths of the peripheral length of the annular furnace. In addition, no tube billet and burning nozzle are present between the charging and discharging furnace doors. A partition wall is placed in the middle. The distance between the charging and 
discharging furnace doors is approximately one-tenth of the peripheral length of the annular furnace.

\section{Dynamic Nonlinear PLS Method}

Given that a linear PLS model cannot correctly describe the nonlinear relationship between independent variable $\mathbf{X}$ and dependent variable $\mathbf{Y}$ ( $\mathbf{X}$ is the variable matrix that affects the heating temperature of the tube billet and $\mathbf{Y}$ is the variable matrix of the heating temperature), nonlinear PLS (NLPLS) method is required. Wold et al. extended the PLS method to the nonlinear field $[13,14]$. Two feasible methods exist in nonlinear PLS methods. One method is to perform array extension for the input matrix, introduce several nonlinear terms of the original variable (e.g., the square term), and then regress the extended input and output matrix through PLS method. If prior knowledge on the relationship of original input variable does not exist, this method cannot be utilized as a reference in the selection of the combined mode and may lead to an oversized dimension of the input matrix and difficulties in processing. The other method is to reserve the linear external model of the PLS method. The internal model is nonlinear. The effect of various input variables on the final tube billet temperature has a different time lag because of the large time lag characteristics of tube billet heating. Accurately predicting the tube billet temperature through traditional PLS method is difficult. In this study, dynamic PLS method was utilized to calculate the lag time of various input channels and significantly improve the model's precision. The algorithm is as follows:

$$
\mathbf{X}=\left[x_{1}^{K 1}, x_{2}^{K 2}, \ldots, x_{p}^{K p}\right]
$$

where $K 1, K 2, \ldots, K p$ are the ratio of lag time to sampling period for sampling variables $x_{1}, x_{2}, \ldots, x_{p}$.

(1) The external relation model is

$$
\begin{aligned}
& X=T P^{T}+E=\sum_{a=1}^{A} t_{a} p_{a}^{T}+E, \\
& Y=U Q^{T}+F=\sum_{a=1}^{A} u_{a} q_{a}^{T}+F
\end{aligned}
$$

where $A$ is the number of reserved eigenvector; $t_{a}(n \times 1)$ and $u_{a}(n \times 1)$ are the score vectors of $X$ and $Y$, respectively; $p_{a}(m \times$ $1)$ and $q_{a}(p \times 1)$ are the load vectors of $X$ and $Y$, respectively; $T(n \times A)$ and $U(n \times A)$ are the score matrixes of $X$ and $Y$, respectively; $P(m \times A)$ and $Q(p \times A)$ are the load matrixes of $X$ and $Y$, respectively; and $E$ and $F$ are the fit residual matrixes of $X$ and $Y$, respectively.

(2) The internal relation model is

$$
\widehat{u}_{a}=f\left(t_{a}\right)+\varepsilon
$$

where $f()$ is the nonlinear function and $\varepsilon$ is the residual.

Given that a neural network is capable of nonlinearity fitting during the modeling of the batch process, nonlinear MPLS method, where the internal model adopts a neural network, has gained extensive applications. Considering that a traditional feed-forward neural network adopts a gradient learning algorithm during training, the parameters in the network need iteration and updating. Training not only consumes much time but also easily results in issues of local minimum and excessive training [15].

\section{OS-ELM-DRPLS Algorithm}

4.1. ELM Algorithm. In supervised batch learning, the learning algorithms employ a finite number of input-output samples for training [16-22]. For $N$ arbitrary distinct samples $\left(x_{i}, t_{i}\right) \in R^{n} \times R^{m}$, where $x_{i}$ is a $n \times 1$ input vector and $t_{i}$ is a $m \times 1$ target vector, if a single hidden layer feed-forward neural network (SLFN) [23-26] with $\widetilde{N}$ hidden nodes can approximate these $N$ samples with zero error, then $\beta_{i}, a_{i}$, and $b_{i}$ exist such that

$$
f_{\widetilde{N}}\left(x_{j}\right)=\sum_{i=1}^{\widetilde{N}} \beta_{i} G\left(a_{i}, b_{i}, x_{j}\right)+\varepsilon_{j}=t_{j} .
$$

In the expression above, $j=1, \ldots, N, a_{i}$, and $b_{i}$ are the learning parameters of the hidden nodes (the weight vector connecting the input node to the hidden node and the threshold of the hidden node) randomly selected according to the proof provided by Huang et al. $\beta_{i}$ is the weight connecting the $i$ th hidden node to the output node. Error term $\varepsilon_{j}$ is added to avoid overfitting the noise in the data. $G\left(a_{i}, b_{i}, x\right)$ is the output of the $i$ th hidden node with respect to input $x$, and $\widetilde{N}$ is the number of hidden nodes that can be determined by trial and error or prior experience. Equation (4) can then be written compactly as

$$
H \beta=T,
$$

where

$$
\begin{gathered}
H\left(a_{1}, \ldots, a_{\widetilde{N}}, b_{1}, \ldots, b_{\widetilde{N}}, x_{1}, \ldots, x_{N}\right) \\
=\left[\begin{array}{ccc}
G\left(a_{1}, b_{1}, x_{1}\right) & \ldots & G\left(a_{\widetilde{N}}, b_{\widetilde{N}}, x_{1}\right) \\
\vdots & \ldots & \vdots \\
G\left(a_{1}, b_{1}, x_{N}\right) & \cdots & \left.G\left(a_{\widetilde{N}}, b_{\widetilde{N}}, x_{N}\right)\right]_{N \times \widetilde{N}}, \\
\beta=\left[\begin{array}{c}
\beta_{1}^{T} \\
\vdots \\
\beta_{\widetilde{N}}^{T}
\end{array}\right]_{\widetilde{N} \times m}, & T=\left[\begin{array}{c}
t_{1}^{T} \\
\vdots \\
t_{N}^{T}
\end{array}\right]_{N \times m} .
\end{array}\right.
\end{gathered}
$$

In the expressions above, $H$ is the hidden layer output matrix of the network; the $i$ th column of $H$ is the $i$ th hidden node's output vector with respect to inputs $x_{1}, x_{2}, \ldots, x_{N}$, and the $j$ th row of $H$ is the output vector of the hidden layer with respect to input $x_{j}$. The hidden node parameters $a_{i}$ and $b_{i}$ need not be tuned during training and may simply be assigned with random values. Equation (5) then becomes a linear system, and the output weights $\beta$ are estimated as

$$
\widetilde{\beta}=H^{+} T \text {, }
$$

where $\mathrm{H}^{+}$is the Moore-Penrose generalized inverse of hidden layer output matrix $H[27,28]$. 
4.2. OS-ELM Algorithm. In actual applications, training data may arrive chunk by chunk or one by one. Hence, the batch ELM algorithm has to be modified and made online sequential for this case $[29,30]$.

Output weight matrix $\widehat{\beta}\left(\widehat{\beta}=H^{+} T\right)$ provided in (7) is a least-squares solution of (5). We consider the case, where $\operatorname{rank}(H)=\widetilde{N}$ is the number of hidden nodes. Under this condition, $\mathrm{H}^{+}$of (7) is provided by

$$
H^{+}=\left(H^{T} H\right)^{-1} H^{T}
$$

If $H^{T} H$ is singular, one can make it nonsingular by selecting a small network size $\widetilde{N}$ or increasing data number $N$ in the initialization phase of OS-ELM. Substituting (8) to (7), $\widehat{\beta}$ becomes

$$
\widehat{\beta}=\left(H^{T} H\right)^{-1} H^{T} T \text {. }
$$

Equation (9) is the least-squares solution to $H \beta=T$. Sequential implementation of (9) results in OS-ELM [31].

Given a chunk of initial training set $\aleph_{0}=\left\{\left(x_{i}, t_{i}\right)\right\}_{i=1}^{N_{0}}$ and $N_{0} \geq \widetilde{N}$, if the batch ELM algorithm is employed, the solution of minimizing $\left\|H_{0} \beta-T\right\|$, which is given by $\beta_{0}=K_{0}^{-1} H_{0}^{T} T_{0}$, where $K_{0}=H_{0}^{T} H_{0}$, must be considered.

We consider another chunk of data $\aleph_{1}=\left\{\left(x_{i}, t_{i}\right)\right\}_{i=N_{0}+1}^{N_{0}+N_{1}}$, where $N_{1}$ is the number of samples in this chunk. The problem involves minimizing

$$
\left\|\left[\begin{array}{l}
H_{0} \\
H_{1}
\end{array}\right] \beta-\left[\begin{array}{l}
T_{0} \\
T_{1}
\end{array}\right]\right\|
$$

Considering both $\aleph_{0}$ and $\aleph_{1}$, output weight $\beta$ becomes

$$
\beta_{1}=K_{1}^{-1}\left[\begin{array}{l}
H_{0} \\
H_{1}
\end{array}\right]^{T}\left[\begin{array}{l}
T_{0} \\
T_{1}
\end{array}\right] \quad \text { where } K_{1}=\left[\begin{array}{l}
H_{0} \\
H_{1}
\end{array}\right]^{T}\left[\begin{array}{l}
H_{0} \\
H_{1}
\end{array}\right] \text {. }
$$

For sequential learning, $\beta_{1}$ should be expressed as a function of $\beta_{0}, K_{1}, H_{1}$, and $T_{1}$ and not as a function of dataset $\aleph_{0} . K_{1}$ can be written as

$$
\begin{aligned}
K_{1} & =\left[\begin{array}{ll}
H_{0}^{T} & H_{1}^{T}
\end{array}\right]\left[\begin{array}{l}
H_{0} \\
H_{1}
\end{array}\right]=K_{0}+H_{1}^{T} H_{1} \\
{\left[\begin{array}{l}
H_{0} \\
H_{1}
\end{array}\right]^{T}\left[\begin{array}{l}
T_{0} \\
T_{1}
\end{array}\right] } & =H_{0}^{T} T_{0}+H_{1}^{T} H_{1}=K_{0} K_{0}^{-1} H_{0}^{T} T_{0}+H_{1}^{T} T_{1} \\
& =K_{0} \beta_{0}+H_{1}^{T} T_{1}=\left(K_{1}-H_{1}^{T} H_{1}\right) \beta_{0}+H_{1}^{T} T_{1} \\
& =K_{1} \beta_{0}-H_{1}^{T} H_{1} \beta_{0}+H_{1}^{T} T_{1} .
\end{aligned}
$$

Combining (11) and (13), $\beta_{1}$ is obtained with

$$
\begin{aligned}
\beta_{1} & =K_{1}^{-1}\left[\begin{array}{l}
H_{0} \\
H_{1}
\end{array}\right]^{T}\left[\begin{array}{l}
T_{0} \\
T_{1}
\end{array}\right]=K_{1}^{-1}\left(K_{1} \beta_{0}-H_{1}^{T} H_{1} \beta_{0}+H_{1}^{T} T_{1}\right) \\
& =\beta_{0}+K_{1}^{-1} H_{1}^{T}\left(T_{1}-H_{1} \beta_{0}\right),
\end{aligned}
$$

where $K_{1}=K_{0}+H_{1}^{T} H_{1}$.

When the $(k+1)$ th chunk of dataset

$$
\aleph_{k+1}=\left\{\left(x_{i}, t_{i}\right)\right\}_{i=\left(\sum_{j=0}^{k} N_{j}\right)+1}^{\sum_{j=1}^{k+1} N_{j}}
$$

is received, where $k \geq 0$ and $N_{k+1}$ denotes the number of samples in the $(k+1)$ th chunk, we have

$$
\begin{gathered}
K_{k+1}=K_{k}+H_{k+1}^{T} H_{k+1}, \\
\beta_{k+1}=\beta_{k}+K_{k+1}^{-1} H_{k+1}^{T}\left(T_{k+1}-H_{k+1} \beta_{k}\right) .
\end{gathered}
$$

$K_{k+1}^{-1}$ rather than $K_{k+1}$ is utilized to compute $\beta_{k+1}$ from $\beta_{k}$ in (16). The update formula for $K_{k+1}^{-1}$ is derived with the Woodbury formula

$$
\begin{aligned}
K_{k+1}^{-1} & =\left(K_{k}+H_{k+1}^{T} H_{k+1}\right)^{-1} \\
& =K_{k}^{-1}-K_{k}^{-1} H_{k+1}^{T}\left(I+H_{k+1} K_{k}^{-1} H_{k+1}^{T}\right)^{-1} \times H_{k+1} K_{k}^{-1} .
\end{aligned}
$$

We let $P_{k+1}=K_{k+1}^{-1}$. The equation for updating $\beta_{k+1}$ can be written as

$$
\begin{gathered}
P_{k+1}=P_{k}-P_{k} H_{k+1}^{T}\left(I+H_{k+1} P_{k} H_{k+1}^{T}\right)^{-1} H_{k+1} P_{k}, \\
\beta_{k+1}=\beta_{k}+P_{k+1} H_{k+1}^{T}\left(T_{k+1}-H_{k+1} \beta_{k}\right) .
\end{gathered}
$$

Equation (18) provides the recursive formula for $\beta_{k+1}$.

4.3. OS-ELM-DRPLS Modeling Steps. The difference of nonlinear DRPLS modeling method based on OS-ELM from linear PLS method is that the former employs ELM to establish the internal nonlinear model and updates the internal and external models. This method reserves the linear external model, extracts the attributive information of the process through PLS, eliminates the colinearity of data, reduces the dimension of the input variable, and then adopts ELM to establish a nonlinear internal model between the input score vector matrix and the output score vector; the nonlinear processing capability of the internal model is enhanced. Thus, OS-ELM-DRPLS method has the advantages of PLS and ELM (i.e., the robustness and feature extraction capability of PLS method and quick nonlinear processing capability of ELM as well as precision accuracy through real-time model update).

The modeling and testing steps of nonlinear DRPLS method based on OS-ELM are as follows. 
(1) Two standardized data matrices, $X \in R^{n \times m}$ and $Y \in$ $R^{n \times p}$, are assigned. The dynamic nonlinear PLS regression model can be expressed as follows:

$$
\mathbf{X}=\left[x_{1}^{K 1}, x_{2}^{K 2}, \ldots, x_{p}^{K p}\right]
$$

where $K 1, K 2, \ldots, K p$ are the ratio of lag time to the sampling period for sampling variables $x_{1}, x_{2}, \ldots, x_{p}$.

(2) The batch data of the batch process are deployed, cross-validation method is implemented to determine the number of latent variables, and linear PLS method is applied to calculate score vector matrices $T$ and $U$ and load vector matrices $P$ and $Q$ for modeling samples $X$ and $Y$ :

$$
\begin{aligned}
& X=T P^{T}+E=\sum_{a=1}^{A} t_{a} p_{a}^{T}+E \\
& Y=U Q^{T}+F=\sum_{a=1}^{A} u_{a} q_{a}^{T}+F .
\end{aligned}
$$

(3) A node number is assigned to the ELM hidden layer and activation function (e.g., sigmoid function), ELM is employed to establish a nonlinear model between internal models $T$ and $U$, and $U=f_{\mathrm{ELM}}(T)$ is obtained, where $f_{\text {ELM }}(\cdot)$ is the nonlinear function indicated by ELM. The hidden nodes in SLFN transform the feature space into another feature space. The original ELM regards the number of nodes as a parameter to be defined. We increase the number of hidden nodes until stop criteria (e.g., residual error reduction) are reached. Meanwhile, the number of hidden nodes is less than $N$.

(4) When one new batch of data $X_{1}, Y_{1}$ is obtained, PLS decomposition is performed, and score and load vectors $T_{1}, U_{1}, P_{1}, Q_{1}$ are obtained:

$$
\begin{aligned}
& X_{1}=T_{1} P_{1}^{T}+E \\
& Y_{1}=U_{1} Q_{1}^{T}+F .
\end{aligned}
$$

According to (18), the OS-ELM algorithm is adopted to update the output layer weight value and the internal model. Weighted mean is conducted on the load matrix of the external model, and external RPLS update, where $w$ is the weight value factor, is achieved. The above steps are repeated, and model update is conducted for every batch:

$$
\begin{aligned}
& P^{T}=w P^{T}+(1-w) P_{1}^{T}, \\
& Q^{T}=w Q^{T}+(1-w) Q_{1}^{T} .
\end{aligned}
$$

(5) Testing data are utilized to verify the model's precision. PLS decomposition is conducted on testing data $X_{2}$, and score vector $T_{2}$ is obtained:

$$
X_{2}=T_{2} P^{T}+E
$$

$T_{2}$ is introduced into the OS-ELM model. $U_{2}=$ $f_{\text {OS-ELM }}\left(T_{2}\right)$ is obtained, and the model prediction value is determined through $\widehat{Y}=U Q^{T}$.
(6) A system error is obtained by comparing $\widehat{Y}$ with the practical output. $K 1, K 2, \ldots, K p$ can vary within $1-n$. After each variation, $x_{1}^{K_{1}}, x_{2}^{K_{2}}, \ldots, x_{p}^{K_{p}}$ are substituted back to (19) for calculation and to obtain an estimation error. Finally, one is obtained by exhausting a group of optimal $K_{1}, K_{2}, \ldots, K_{p}$ values to minimize the model estimation error:

$$
W=\sum_{i=1}^{n / 2}|\widehat{\mathbf{Y}}(i)-\mathbf{Y}(i)|
$$

Model parameters $K_{1}, K_{2}, \ldots, K_{p}$ and $\beta$ of the OS-ELMDRPLS model are then obtained through the aforementioned calculation.

\section{Prediction and Control of Tube Billet Heating Quality Based on OS- ELM-DRPLS Model}

5.1. Introduction of the Site and Selection of Measuring Points. In the seamless tube subcompany of Baosteel, the designed output of an annular furnace was $160 \mathrm{t} / \mathrm{h}$. Its intermediate diameter was $35 \mathrm{~m}$, and the effective width of hearth was $4.5 \mathrm{~m}$. The hearth was divided into six burning control sections. The diameter of the heated tube billet was $178 \mathrm{~mm}$. The temperature upon entering the furnace was $20^{\circ} \mathrm{C}$, and the maximum temperature upon leaving the furnace was $1280^{\circ} \mathrm{C}$. In the annular furnace, mixed gas that consists of $52 \%$ blast furnace gas, $13 \%$ converter gas, and $34.8 \%$ coke oven gas was utilized. The composition of the blast furnace gas was $23.5 \% \mathrm{CO}, 2 \% \mathrm{H}_{2}, 19.5 \% \mathrm{CO}_{2}$, and $35 \% \mathrm{~N}$; the composition of coke oven gas was $53 \% \mathrm{H}_{2}, 29.2 \mathrm{CH}_{4}, 2.8 \%$ weight carbon hydride, $7.5 \% \mathrm{CO}, 2.0 \% \mathrm{CO}_{2}, 0.6 \% \mathrm{O}_{2}$, and $4.4 \% \mathrm{~N}_{2}$. The composition of converter gas was $56 \% \mathrm{CO}, 24 \% \mathrm{~N}_{2}$, and $19.7 \% \mathrm{CO}_{2}$. The specific technical parameters are shown in Table 1.

The final exit temperature of the tube billet was predicted through OS-ELM-DRPLS method. First, the variation in the tube billet temperature was reflected, and the measured variables were easily obtained. On one hand, gas could not be obtained through the peep holes because the peep holes in the furnace were closed. On the other hand, opening of the furnace door to obtain gas affects the testing precision because of the absorption of cold air. Therefore, the measuring points in the site were set at the lighting holes of burning nozzles in the external surrounding furnace walls. Six flow rate detecting points were set for the burning nozzles. Nine thermocouples were mounted in the six working sections to measure the temperature inside the furnace cavity. The specific positions of flow rate and furnace temperature are shown in Figure 2. Fifteen measuring variables were selected to predict the final tube billet exit temperature. $x_{1}-x_{6}$ were measuring points for numbers 1-6 burning nozzle flow rate, and $x_{7}-x_{15}$ were measuring points for numbers 1-9 furnace cavity temperature. The variable table is shown in Table 2. After selecting the measuring variables and gathering site 
TABLE 1: Main technical parameters of annular furnace.

\begin{tabular}{ll}
\hline Furnace output & $160 \mathrm{t} / \mathrm{h}$ \\
\hline Specification of tube billet & $\Phi 175 \mathrm{~mm}, 860-4500 \mathrm{~mm}$ in length, maximum weight per piece $850 \mathrm{~kg}$ \\
\hline Furnace size & $\begin{array}{l}\text { Intermediate diameter } 35 \mathrm{~m} \text {, effective width of furnace cavity } 5 \mathrm{~m}, \text { height of furnace } \\
\text { cavity } 3 \mathrm{~m} \text { (one section in the preheating zone), } 2.5 \mathrm{~m}(2 \mathrm{sections}), 2 \mathrm{~m}(3-6 \\
\text { sections), total number of hearth batch bins } 391, \text { number of tube billets } 381 \text { pieces }\end{array}$ \\
\hline Calorific value of combustion & Heavy oil $37620 \mathrm{Kj} / \mathrm{kg}$, mixed gas $9196 \mathrm{Kj} / \mathrm{m}^{3}$ \\
\hline Demand of combustion & Heavy oil $6755 \mathrm{~kg} / \mathrm{h}$, mixed gas $30545 \mathrm{~m}^{3} / \mathrm{h}$ \\
\hline Arrangement of burning nozzle & $\begin{array}{l}\text { Total of } 96 \text { side burning nozzles for either oil or gas used in sections } 1-6 \text {; heat is not } \\
\text { provided in the preheating zone }\end{array}$ \\
\hline Maximum furnace cavity temperature & Approximately $1400^{\circ} \mathrm{C}$ \\
\hline Temperature of tube billet & $\begin{array}{l}\text { Enter furnace at } 20^{\circ} \mathrm{C}, \text { leave furnace at } 1280^{\circ} \mathrm{C}, \text { cross-section temperature difference } \\
\text { of leaving furnace } \pm 10^{\circ} \mathrm{C}\end{array}$ \\
\hline Charging and discharging rhythm & Maximum 270 piece $/ \mathrm{h}$, equivalent to discharging interval of $13.3 \mathrm{~s} /$ piece \\
\hline
\end{tabular}

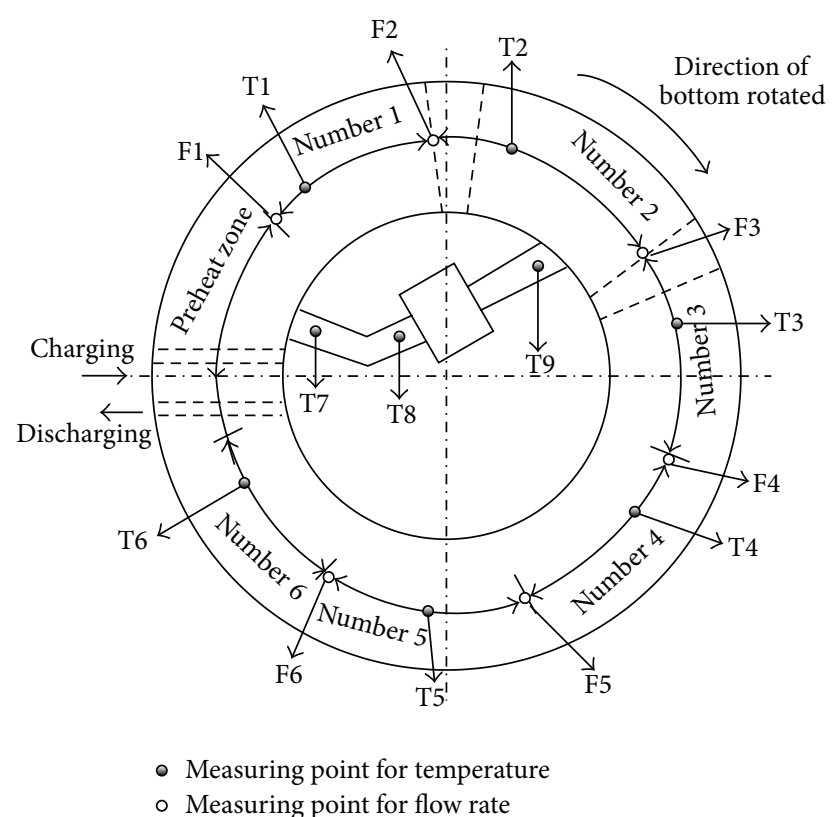

FIGURE 2: Measuring point distribution diagram for the annular furnace.

production data, OS-ELM-DRPLS method was applied to the prediction model of tube billet temperature.

5.2. Establishment and Checking of the Tube Billet Final Temperature Prediction Model. The production data for 70 pieces of tube billets produced by Baosteel in March, 2013, were utilized. The first forty samples were utilized as training data to establish the prediction model of tube billet final temperature. The last thirty samples were used for model update. Lump update was employed. Every group of five was considered a lump. The model was updated. The last thirty samples acted as the testing samples to check the precision of model prediction. Prior to modeling, data were expanded, they were standardized-processed, and they underwent cross
TABLE 2: Variables in the modeling of tube billet final temperature.

\begin{tabular}{|c|c|c|c|}
\hline Ser. number & $\begin{array}{c}\text { Variable } \\
\text { name }\end{array}$ & Variable meaning & Unit \\
\hline 1 & $x_{1}$ & $\begin{array}{l}\text { Number } 1 \text { burning nozzle flow } \\
\text { rate }\end{array}$ & $\mathrm{m}^{3} / \mathrm{h}$ \\
\hline 2 & $x_{2}$ & $\begin{array}{c}\text { Number } 2 \text { burning nozzle flow } \\
\text { rate }\end{array}$ & $\mathrm{m}^{3} / \mathrm{h}$ \\
\hline 3 & $x_{3}$ & $\begin{array}{c}\text { Number } 3 \text { burning nozzle flow } \\
\text { rate }\end{array}$ & $\mathrm{m}^{3} / \mathrm{h}$ \\
\hline 4 & $x_{4}$ & $\begin{array}{c}\text { Number } 4 \text { burning nozzle flow } \\
\text { rate }\end{array}$ & $\mathrm{m}^{3} / \mathrm{h}$ \\
\hline 5 & $x_{5}$ & $\begin{array}{l}\text { Number } 5 \text { burning nozzle flow } \\
\text { rate }\end{array}$ & $\mathrm{m}^{3} / \mathrm{h}$ \\
\hline 6 & $x_{6}$ & $\begin{array}{l}\text { Number } 6 \text { burning nozzle flow } \\
\text { rate }\end{array}$ & $\mathrm{m}^{3} / \mathrm{h}$ \\
\hline 7 & $x_{7}$ & $\begin{array}{l}\text { Number } 1 \text { furnace cavity } \\
\text { temperature }\end{array}$ & ${ }^{\circ} \mathrm{C}$ \\
\hline 8 & $x_{8}$ & $\begin{array}{l}\text { Number } 2 \text { furnace cavity } \\
\text { temperature }\end{array}$ & ${ }^{\circ} \mathrm{C}$ \\
\hline 9 & $x_{9}$ & $\begin{array}{l}\text { Number } 3 \text { furnace cavity } \\
\text { temperature }\end{array}$ & ${ }^{\circ} \mathrm{C}$ \\
\hline 10 & $x_{10}$ & $\begin{array}{l}\text { Number } 4 \text { furnace cavity } \\
\text { temperature }\end{array}$ & ${ }^{\circ} \mathrm{C}$ \\
\hline 11 & $x_{11}$ & $\begin{array}{l}\text { Number } 5 \text { furnace cavity } \\
\text { temperature }\end{array}$ & ${ }^{\circ} \mathrm{C}$ \\
\hline 12 & $x_{12}$ & $\begin{array}{l}\text { Number } 6 \text { furnace cavity } \\
\text { temperature }\end{array}$ & ${ }^{\circ} \mathrm{C}$ \\
\hline 13 & $x_{13}$ & $\begin{array}{l}\text { Number } 7 \text { furnace cavity } \\
\text { temperature }\end{array}$ & ${ }^{\circ} \mathrm{C}$ \\
\hline 14 & $x_{14}$ & $\begin{array}{l}\text { Number } 8 \text { furnace cavity } \\
\text { temperature }\end{array}$ & ${ }^{\circ} \mathrm{C}$ \\
\hline 15 & $x_{15}$ & $\begin{array}{c}\text { Number } 9 \text { furnace cavity } \\
\text { temperature }\end{array}$ & ${ }^{\circ} \mathrm{C}$ \\
\hline
\end{tabular}

checking. The number of PLS potential variables was determined to be 4 . The number of ELM hidden layer nodes was 10. The excitation function was a sigmoid function. The ratio 
TABLE 3: RMSE and modeling time of different models.

\begin{tabular}{lcc}
\hline Method & RMSE (test) & Time/s \\
\hline RPLS & 10.2 & 0.2132 \\
RBF-PLS & 4.2 & 3.0692 \\
OS-ELM-DRPLS & 3.1 & 0.6239 \\
\hline
\end{tabular}

of lag time of $K_{1}, K_{2}, \ldots, K_{p}$ in (19) was calculated in formulas equation (25).

The same data were tested with RPLS, RBF-PLS, and OS-ELM-DRPLS methods. The predicted mean square error and modeling time are shown in Table 3. Although the three methods meet the requirements of industrial application, OS-ELM-RPLS method exhibits better expansion capability, prediction precision, and nonlinear fitting capability for industrial application than RPLS method. Compared with nonlinear RBF-PLS method, the training time in OS-ELMRPLS method is shorter. OS-ELM-RPLS method can achieve rapid modeling and model update and is significant to the intermittent production processes, such as tube billet heating:

$$
\begin{aligned}
& {\left[K_{1}, K_{2}, \ldots, K_{15}\right]} \\
& \quad=[58,55,51,46,42,36,61,56,51,45,39,35,52,58,60] .
\end{aligned}
$$

The unit of $\left[K_{1}, K_{2}, \ldots, K_{15}\right]$ is the sample time. Figure 3 shows a comparison between regression data and practical modeling data using RPLS and OS-ELM-DRPLS models. The maximum error was $6.9^{\circ} \mathrm{C}$ and the mean error was $2.3^{\circ} \mathrm{C}$, which meet the requirements of the production site. To further verify the accuracy of the model, new data were introduced into the model and substituted into the following equation to obtain estimation value $\widehat{Y}_{\text {new }}$ of the new data. The comparison with $Y_{\text {new }}$ is shown in Figure 4. The maximum error was $9.8^{\circ} \mathrm{C}$ and the mean error was $3.1^{\circ} \mathrm{C}$, which meet the requirements of the production site:

$$
\widehat{Y}_{\text {new }}=f_{\text {OS-ELM-RDPLS }}\left(X_{\text {new }}\right) \text {. }
$$

5.3. Predicted Control of Tube Billet Final Temperature. The aforementioned data indicate that tube billet exit temperature often fluctuates in the temperature range of $1200^{\circ} \mathrm{C}$ to $1300^{\circ} \mathrm{C}$ and often deviates from the ideal piercing temperature $\left(1270^{\circ} \mathrm{C}\right)$. Such condition degrades the quality of the tube. The tube billet exit temperature should be controlled within the temperature range of $1255^{\circ} \mathrm{C}$ to $1295^{\circ} \mathrm{C}$. The gas flow rate can be adjusted according to the prediction, practical measuring, and target temperatures. Its control period was $1 \mathrm{~s}$. An ELM model predicted controller (EPC) was designed for the annular furnace system with the OS-ELM-DRPLS model predictor (EMP), as shown in Figure 5.

The basic operating principle of predictive control is to generate a sequence of control signals at each sample interval that optimize the control effort to follow the reference trajectory exactly $[32,33]$. The ELM model predictive control law was obtained by minimizing the following predictive performance criterion:

$$
\begin{aligned}
J(k) & =\frac{1}{2} \sum_{p=0}^{N_{p}}(r(k+p)-\widehat{y}(k+p))^{2} \\
& =\frac{1}{2}(R(k)-Y(k))^{T}(R(k)-Y(k))=\frac{1}{2} E^{T}(k) E(k),
\end{aligned}
$$

where

$$
\begin{gathered}
R(k)=\left[\begin{array}{llll}
r(k) & r(k+1) & \cdots & r\left(k+N_{p}\right)
\end{array}\right]^{T}, \\
Y(k)=\left[\begin{array}{llll}
\hat{y}(k) & \hat{y}(k+1) & \cdots & \hat{y}\left(k+N_{p}\right)
\end{array}\right]^{T}, \\
E(k)=\left[\begin{array}{llll}
r(k)-\hat{y}(k) & r(k+1)-\hat{y}(k+1) & \cdots & r\left(k+N_{p}\right)-\hat{y}\left(k+N_{p}\right)
\end{array}\right]^{T} .
\end{gathered}
$$

$N_{p}$ is the predictive output horizon, $r(k+p)$ is the input reference signal at discrete time $k+p$, and $\widehat{y}(k+p)$ is the $p$ step-ahead prediction of $y(k)$. In general, $N_{p}$ is selected to include all responses that are significantly affected by the present control. In this study, $N_{p}$ is $\min (K 1, K 2, \ldots, K 15)=$ 35.

The control, $u(k)=\left[\begin{array}{llll}u(k) & u(k+1) & \cdots & u\left(k+N_{p}\right)\end{array}\right]^{T}$, was obtained from the optimization of the cost function (29) based on gradient descent method; that is,

$$
\begin{aligned}
u(k) & =u(k-1)+\Delta u(k)=u(k-1)+\eta \frac{\partial Y^{T}(k)}{\partial u(k)} E(k) \\
& =u(k-1)+\eta C^{T}(k) E(k),
\end{aligned}
$$

where

$$
\begin{aligned}
C(k) & =\frac{\partial Y^{T}(k)}{\partial u(k)} \\
& =\left[\begin{array}{cccc}
\frac{\partial \hat{y}(k)}{\partial u(k)} & \frac{\partial \hat{y}(k)}{\partial u(k+1)} & \cdots & \frac{\partial \hat{y}(k)}{\partial u\left(k+N_{p}\right)} \\
\frac{\partial \hat{y}(k+1)}{\partial u(k)} & \frac{\partial \hat{y}(k+1)}{\partial u(k+1)} & \cdots & \frac{\partial \hat{y}(k+1)}{\partial u\left(k+N_{p}\right)} \\
\vdots & \vdots & \ddots & \vdots \\
\frac{\partial \hat{y}\left(k+N_{p}\right)}{\partial u(k)} & \frac{\partial \hat{y}\left(k+N_{p}\right)}{\partial u(k+1)} & \cdots & \frac{\partial \hat{y}\left(k+N_{p}\right)}{\partial u\left(k+N_{p}\right)}
\end{array}\right] .
\end{aligned}
$$




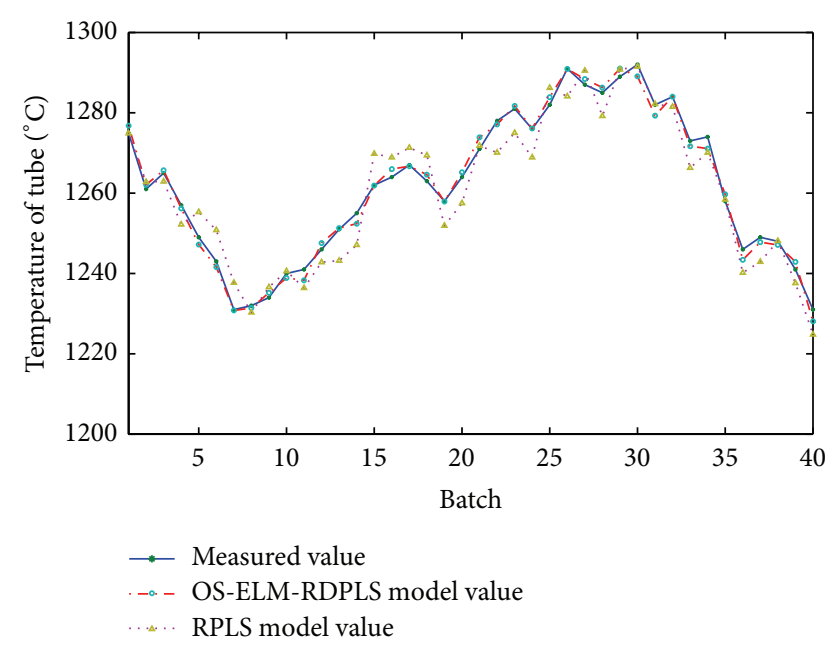

FIgURE 3: Comparison diagram of modeling data.

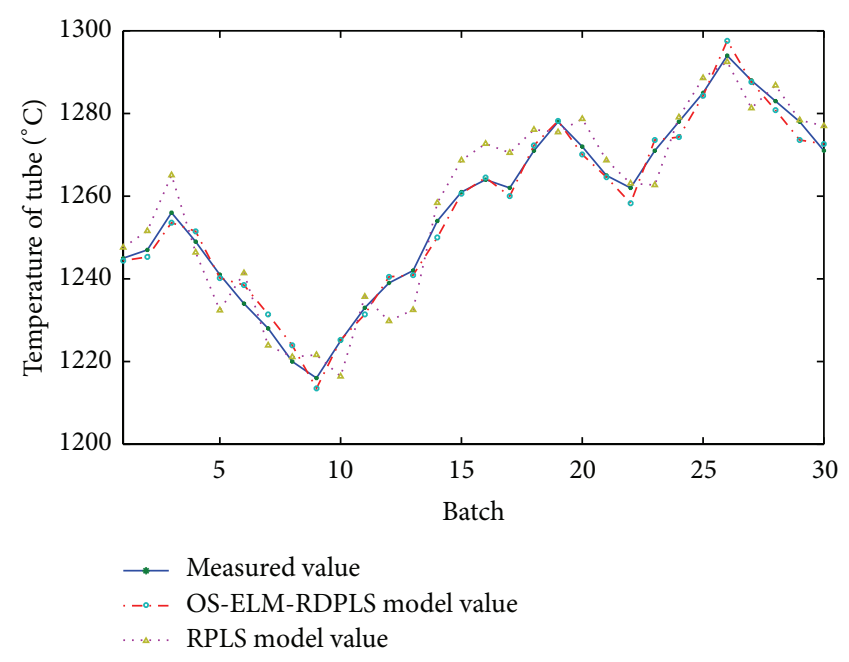

FIGURE 4: Comparison diagram of checking data.

To reduce the computational load of EPC, we let $u\left(k+N_{p}\right)=$ $\cdots=u(k+1)=u(k)$. The EPC controller is expressed in the form

$$
u(k)=u(k-1)+\eta C^{T}(k) E(k),
$$

where

$$
C(k)=\left[\begin{array}{llll}
\frac{\partial \hat{y}(k)}{\partial u(k)} & \frac{\partial \hat{y}(k+1)}{\partial u(k)} & \cdots & \frac{\partial \hat{y}\left(k+N_{p}\right)}{\partial u(k)}
\end{array}\right]^{T} .
$$

A schematic of the proposed PLC-based temperature control system is shown in Figure 6. The actual temperature control system of the annular furnace is depicted in Figure 7. SIMATIC S7-400 was selected as the PLC of the control system. The entire system is mainly composed of a PLC master station, a remote I/O station, an operator station, a programmer and communication bus, and other components. The main modules of PLC include nine slot bases (UR2), a 4 A power supply module (PS407), a central

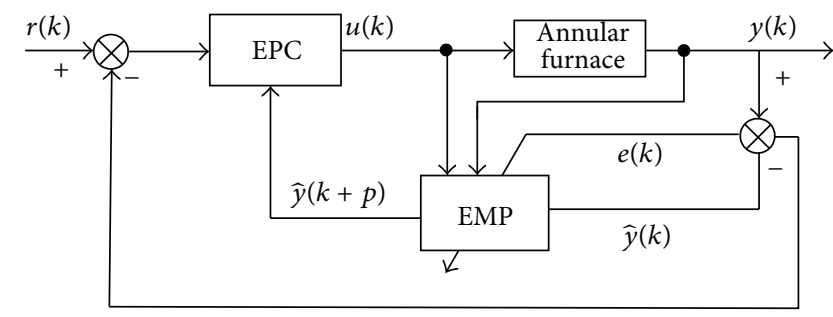

FIGURE 5: Architecture of the annular furnace employing OS-ELMDRPLS-based predictive control.

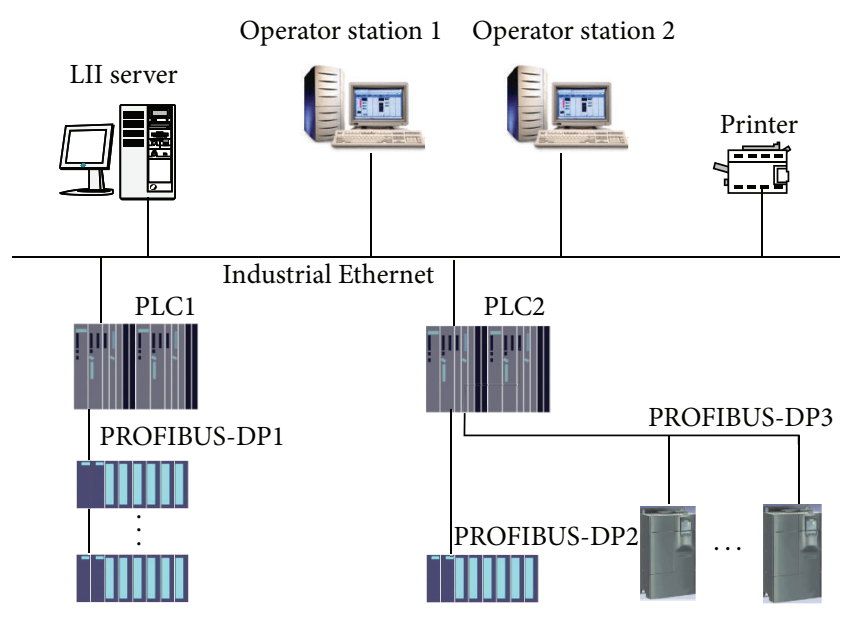

FIGURE 6: Schematic of the PLC-based temperature control system.

processor (CPU416-2DP), $1 \mathrm{M}$ memory card, and a network communication module (CP443-1). The main modules of I/O expansion include a power supply module (PS307), an interface module (IM153-1), a digital input module (SM321 DC24V $\times$ DI16), a digital output module (SM322 DC24V $\times$ DO16), a counter function module (8CH FM350-2), an eight-thermocouple input module (SM331), an eight-RTD input module (SM331), and a four-output module (SM332). The main modules of the workstation include a CPU, (Intel Core i7-930, $2.8 \mathrm{GHz} \times 4$ ), hard disk (WD 2TB), memory (Kingston $8 \mathrm{~GB})$, color LED (24", $1280 \times 1024$ resolution), and a net card (Siemens 10/100 MB). The main module of communication includes Ethernet SINEC H1 and field bus PROFIBUS-DP. The main Software programs are Windows 2003 Prof, STEP7 V5.4, and WINCC6.1.

The tube billet exit temperature should be controlled as best as possible within the temperature range of $1255^{\circ} \mathrm{C}$ to $1295^{\circ} \mathrm{C}$. Thirty tube billets were controlled by ELM model predicted control. A thermocouple was "buried" in a tube billet. The temperature course of the tube billet with the buried thermocouple is shown in Figure 8. In position 30, the predicted temperature of the tube billet is 1211. OS-ELMDRPLS-based predictive control algorithm was employed to make the tube billet reach the lowest required temperature $\left(1255^{\circ} \mathrm{C}\right)$. By adjusting the input, the temperature of the tube billet reached $1265^{\circ} \mathrm{C}$. The variation in tube billet temperature after introducing temperature compensation control is shown in Figure 9. The variation in tube billet temperature after 


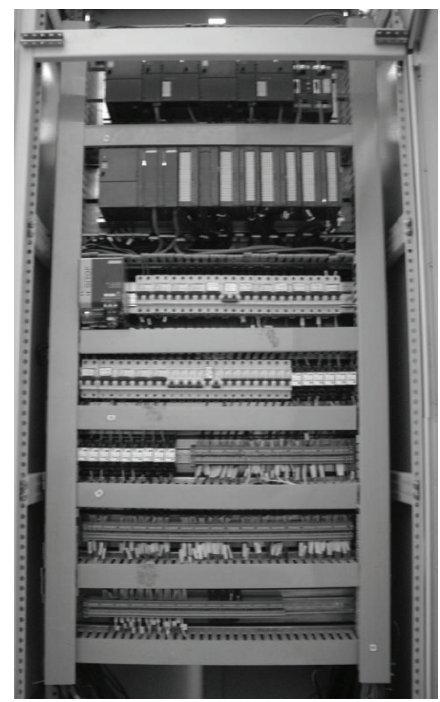

FIGURE 7: Actual temperature control system of the annular furnace.

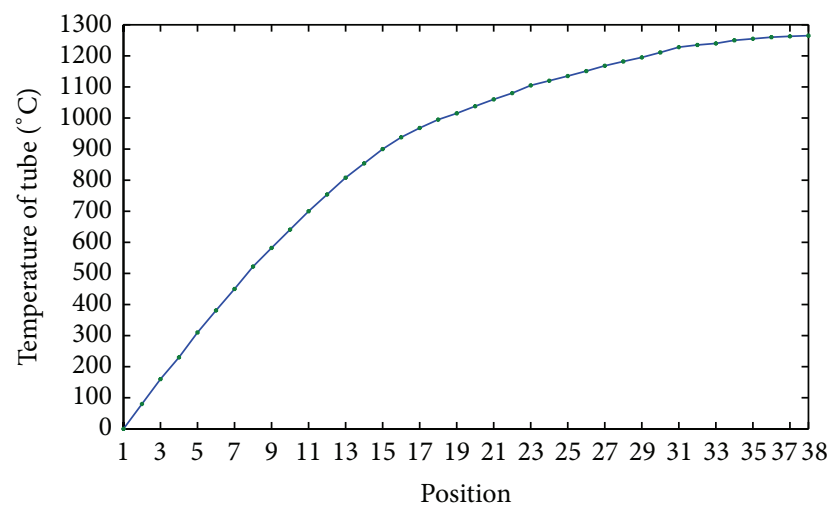

Figure 8: Temperature course of the tube billet with a thermocouple.

introducing PID temperature control is shown in Figure 10. The effect of predicted control is better than that of the PID method.

Figure 9 shows that the tube billet exit temperature basically fluctuates in the range of $\left[1255^{\circ} \mathrm{C}, 1295^{\circ} \mathrm{C}\right]$; the tube billet heating quality is better than that before prediction control and meets the requirements of piercing production for tubes.

\section{Conclusion}

Measuring and controlling tube billet heating temperature are difficult because of the complex reaction mechanism during the heating process in an annular furnace. A tube billet final temperature prediction model was established in this study through OS-ELM-DRPLS modeling method. An OS-ELMDRPLS-based predictive controller for the control of tube billet temperature was also systematically developed. The tube billet heating quality increased to a certain extent. This finding lays the foundation for the improvement of seamless

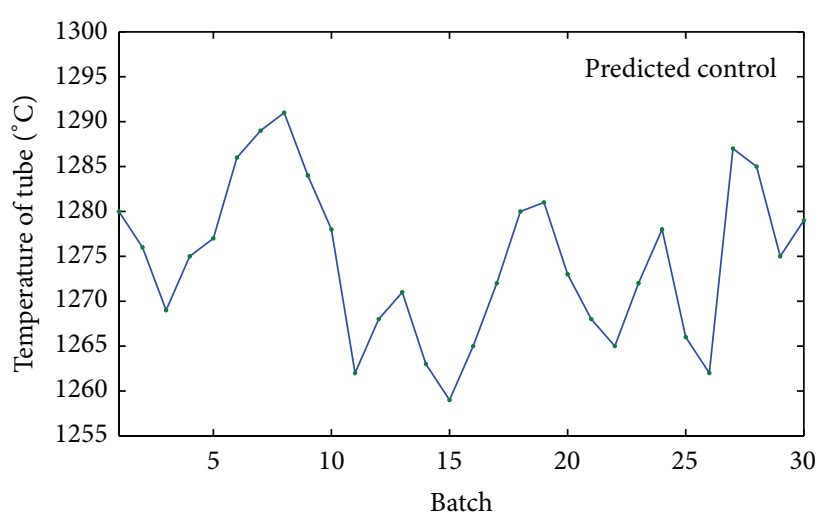

FIGURE 9: Temperature of the tube billet after introducing temperature compensation control.

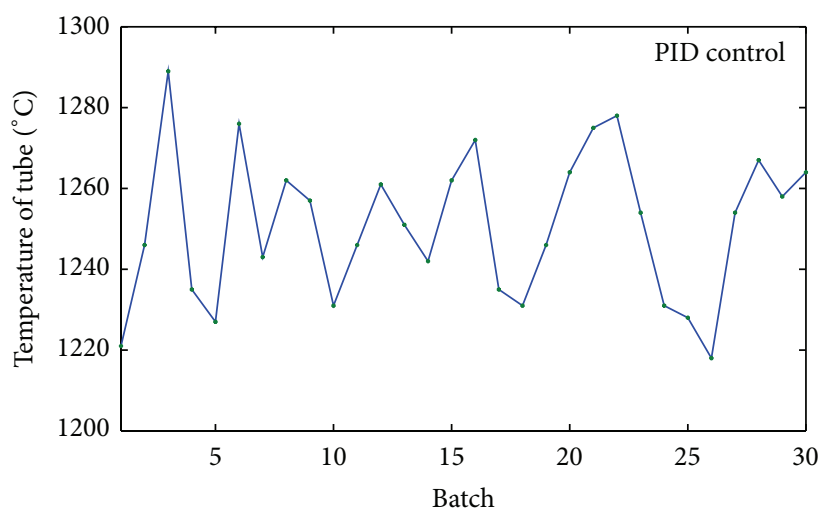

FIgURE 10: Temperature of the tube billet of PID method.

tube quality. After the developed model was compiled into a universal module through the advanced computer language of the configuration software, the modules not only assisted in production by guiding front line workers to operate manually but also formed a perfect close loop control circuit together with the heating furnace model and controller. Hence, tube billet heating quality was improved effectively. Experimentation proved that this method is feasible. This modeling method is also versatile and can be extended to other processes with a large time lag.

\section{Conflict of Interests}

The authors declare that there is no conflict of interests regarding the publication of this paper.

\section{Acknowledgments}

This research is supported by the National Natural Science Foundation of China (Grant nos. 61203214, 41371437, and 61304121) and Provincial Science and Technology Department of Education Projects, the General Project (L2013101). 


\section{References}

[1] A. D. Acharya and S. Chattopadhyay, "Reheat furnace temperature control and performance at Essar Steel," Iron and Steel Engineer, vol. 75, no. 11, pp. 31-36, 1998.

[2] W. C. Chen, I. V. Samarasekera, A. Kumar, and E. B. Hawbolt, "Mathematical modelling of heat flow and deformation during rough rolling," Ironmaking and Steelmaking, vol. 20, no. 2, pp. 113-125, 1993.

[3] A. Jaklič, B. Glogovac, T. Kolenko, B. Zupančič, and B. Težak, "A simulation of heat transfer during billet transport," Applied Thermal Engineering, vol. 22, no. 7, pp. 873-883, 2002.

[4] B. Zhang, Z. G. Chen, and L. Y. Xu, "The modeling and control of a reheating furnace," in Proceedings of the American Control Conference, 2002.

[5] B. Zhang, J. C. Wang, and J. M. Zhang, "Dynamic model of reheating furnace based on fuzzy system and genetic algorithm," Control Theory \& Application, vol. 20, no. 2, pp. 293-296, 1998 (Chinese).

[6] H. J. Wick, "Estimation of ingot temperature in a soaking pit using an extended Kalman filter," in Proceedings of the 8th Triennial World Congress of the International Federation of Automatic Control, 1981.

[7] D. Xiao, Y. H. Yang, and Z. Z. Mao, "A model for billet temperature of prediction of heating-furnace based on improved PCR method," Information and Control, vol. 34, no. 3, pp. 340-343, 2005 (Chinese).

[8] Y.-W. Chen and T.-Y. Chai, "Preprocessing of operation data in heating furnace," Control Theory and Applications, vol. 29, no. 1, pp. 114-118, 2012 (Chinese).

[9] G. M. Cui and G. B. Ding, "Research on the optimal control of tube billet temperature for rotary reheating furnace," in Advanced Electrical and Electronics Engineering, vol. 87 of Lecture Notes in Electrical Engineering, pp. 471-477, Springer, Berlin, Germany, 2011.

[10] H. Iwamoto, O. Sugiyama, R. Nakanishi, and T. Okuyama, "Automatic control system of billet reheating rotary hearth furnace," in Proceedings of the International Conference on Industrial Electronics, Control, Instrumentation, 1992.

[11] F. He, A. Xu, H. Wang, D. He, and N. Tian, "End temperature prediction of molten steel in LF based on CBR," Steel Research International, vol. 83, no. 11, pp. 1079-1086, 2012.

[12] W. Lv, Z. Mao, and P. Yuan, "Ladle furnace steel temperature prediction model based on partial linear regularization networks with sparse representation," Steel Research International, vol. 83, no. 3, pp. 288-296, 2012.

[13] S. Wold, N. Kettaneh-Wold, and B. Skagerberg, "Nonlinear PLS modeling," Chemometrics and Intelligent Laboratory Systems, vol. 7, no. 1-2, pp. 53-65, 1989.

[14] S. J. Qin, "Recursive PLS algorithms for adaptive data modeling," Computers \& Chemical Engineering, vol. 22, no. 4-5, pp. 503-514, 1998.

[15] B. Hu, Z. Zhao, and J. Liang, "Multi-loop nonlinear internal model controller design under nonlinear dynamic PLS framework using ARX-neural network model," Journal of Process Control, vol. 22, no. 1, pp. 207-217, 2012.

[16] G.-B. Huang, Q.-Y. Zhu, and C.-K. Siew, "Extreme learning machine: theory and applications," Neurocomputing, vol. 70, no. 1-3, pp. 489-501, 2006.

[17] Y. Yu, T.-M. Choi, and C.-L. Hui, "An intelligent quick prediction algorithm with applications in industrial control and loading problems," IEEE Transactions on Automation Science and Engineering, vol. 9, no. 2, pp. 276-287, 2012.

[18] J. Zhai, H. Xu, and Y. Li, "Fusion of extreme learning machine with fuzzy integral," International Journal of Uncertainty, Fuzziness and Knowlege-Based Systems, vol. 21, supplement 2, pp. 2334, 2013.

[19] J.-H. Zhai, H.-Y. Xu, and X.-Z. Wang, "Dynamic ensemble extreme learning machine based on sample entropy," Soft Computing, vol. 16, no. 9, pp. 1493-1502, 2012.

[20] J. W. Cao, T. Chen, and J. Fan, "Fast online learning algorithm for landmark recognition based on BoW framework," in Proceedings of the 9th IEEE Conference on Industrial Electronics and Applications, June 2014.

[21] Y. Jin, J. W. Cao, Q. Q. Ruan, and X. Q. Wang, "Cross-modality 2D-3D face recognition via multiview smooth discriminant analysis based on ELM," Journal of Electrical and Computer Engineering, vol. 2014, Article ID 584241, 9 pages, 2014.

[22] J. Cao and L. Xiong, "Protein sequence classification with improved extreme learning machine algorithms," BioMed Research International, vol. 2014, Article ID 103054, 12 pages, 2014.

[23] Y. Yang, Y. Wang, and X. Yuan, "Bidirectional extreme learning machine for regression problem and its learning effectiveness," IEEE Transactions on Neural Networks and Learning Systems, vol. 23, no. 9, pp. 1498-1505, 2012.

[24] G.-B. Huang, H. Zhou, X. Ding, and R. Zhang, "Extreme learning machine for regression and multiclass classification," IEEE Transactions on Systems, Man, and Cybernetics Part B: Cybernetics, vol. 42, no. 2, pp. 513-529, 2012.

[25] G.-B. Huang, "An insight into extreme learning machines: random neurons, random features and kernels," Cognitive Computation, vol. 6, no. 3, pp. 376-390, 2014.

[26] G. Huang, S. Song, J. N. D. Gupta, and C. Wu, "Semisupervised and unsupervised extreme learning machines," IEEE Transactions on Cybernetics, 2014.

[27] H.-X. Tian and Z.-Z. Mao, "An ensemble ELM based on modified AdaBoost.RT algorithm for predicting the temperature of molten steel in ladle furnace," IEEE Transactions on Automation Science and Engineering, vol. 7, no. 1, pp. 73-80, 2010.

[28] G. Feng, Z. Qian, and N. Dai, "Reversible watermarking via extreme learning machine prediction," Neurocomputing, vol. 82, no. 4, pp. 62-68, 2012.

[29] N.-Y. Liang, G.-B. Huang, P. Saratchandran, and N. Sundararajan, "A fast and accurate online sequential learning algorithm for feed forward networks," IEEE Transactions on Neural Networks, vol. 17, no. 6, pp. 1411-1423, 2006.

[30] J. Zhao, Z. Wang, and D. S. Park, "Online sequential extreme learning machine with forgetting mechanism," Neurocomputing, vol. 87, pp. 79-89, 2012.

[31] S. J. Xie, J. Yang, H. Gong, S. Yoon, and D. S. Park, "Intelligent fingerprint quality analysis using online sequential extreme learning machine," Soft Computing, vol. 16, no. 9, pp. 1555-1568, 2012.

[32] M. Khalid, S. Omatu, and R. Yusof, "MIMO furnace control with neural networks," IEEE Transactions on Control Systems Technology, vol. 1, no. 4, pp. 238-245, 1993.

[33] C.-H. Lu, C.-C. Tsai, C.-M. Liu, and Y.-H. Charng, "Neuralnetwork-based predictive controller design: an application to temperature control of a plastic injection molding process," Asian Journal of Control, vol. 12, no. 6, pp. 680-691, 2010. 


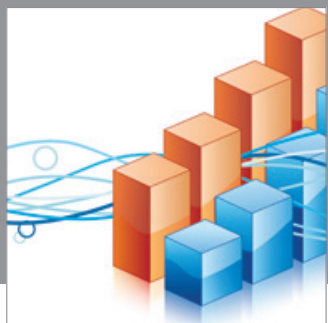

Advances in

Operations Research

mansans

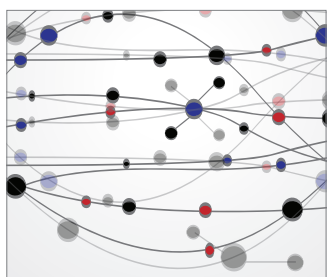

The Scientific World Journal
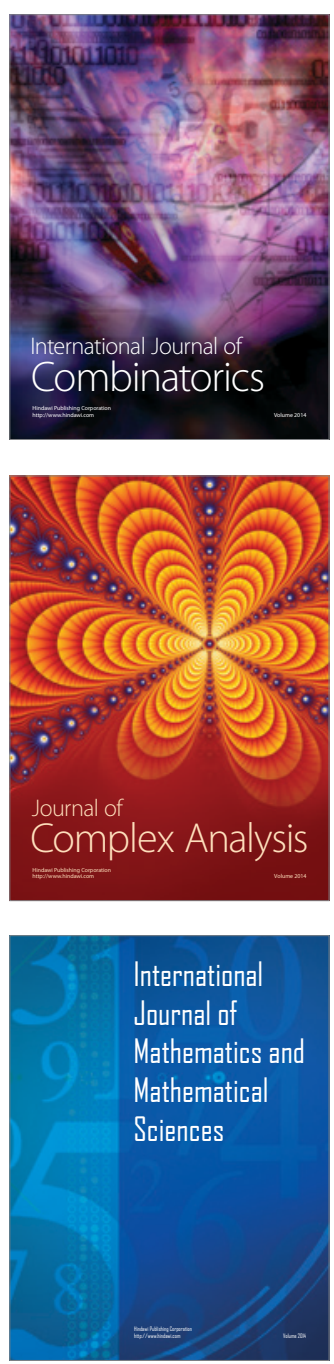
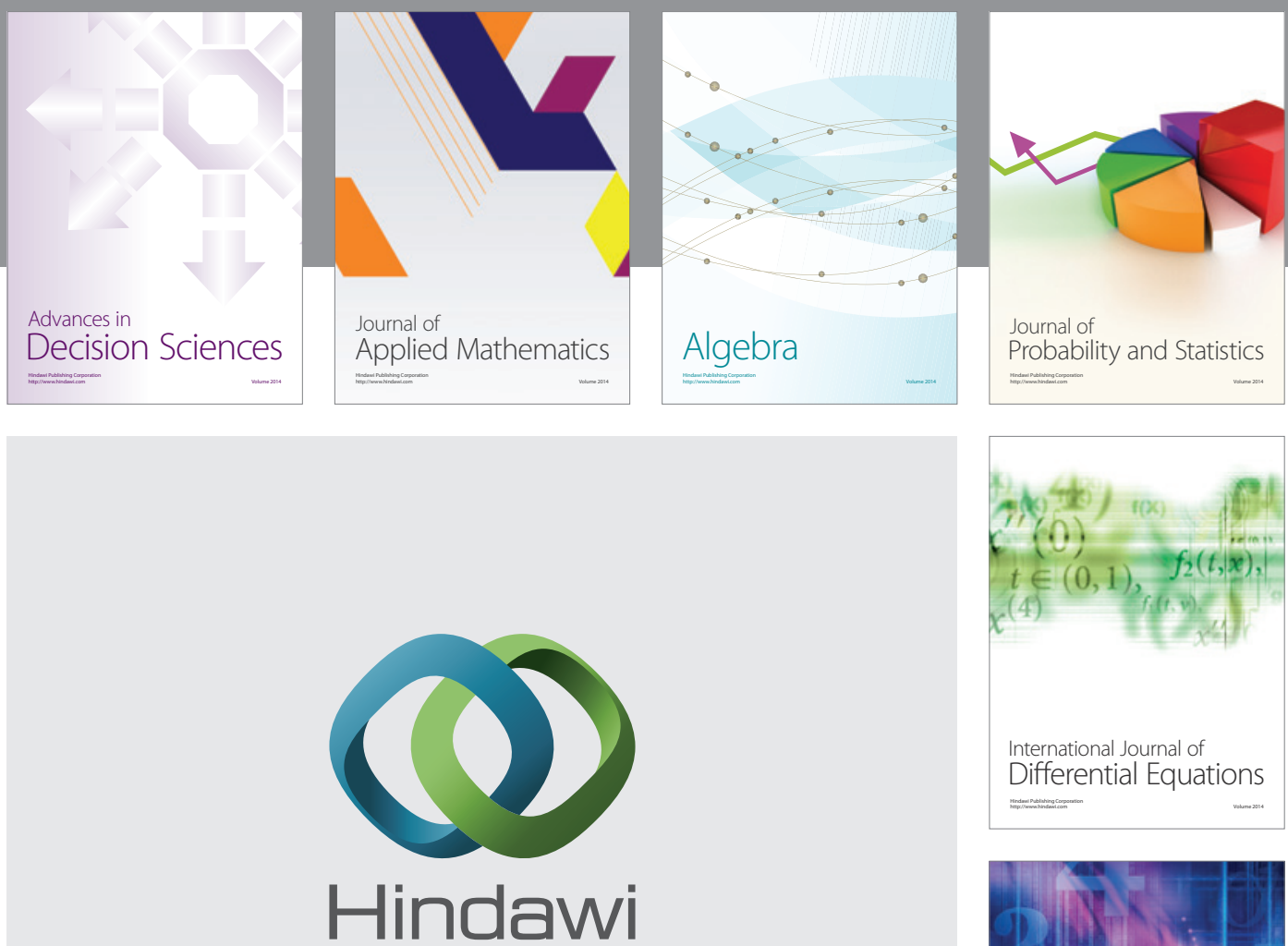

Submit your manuscripts at http://www.hindawi.com
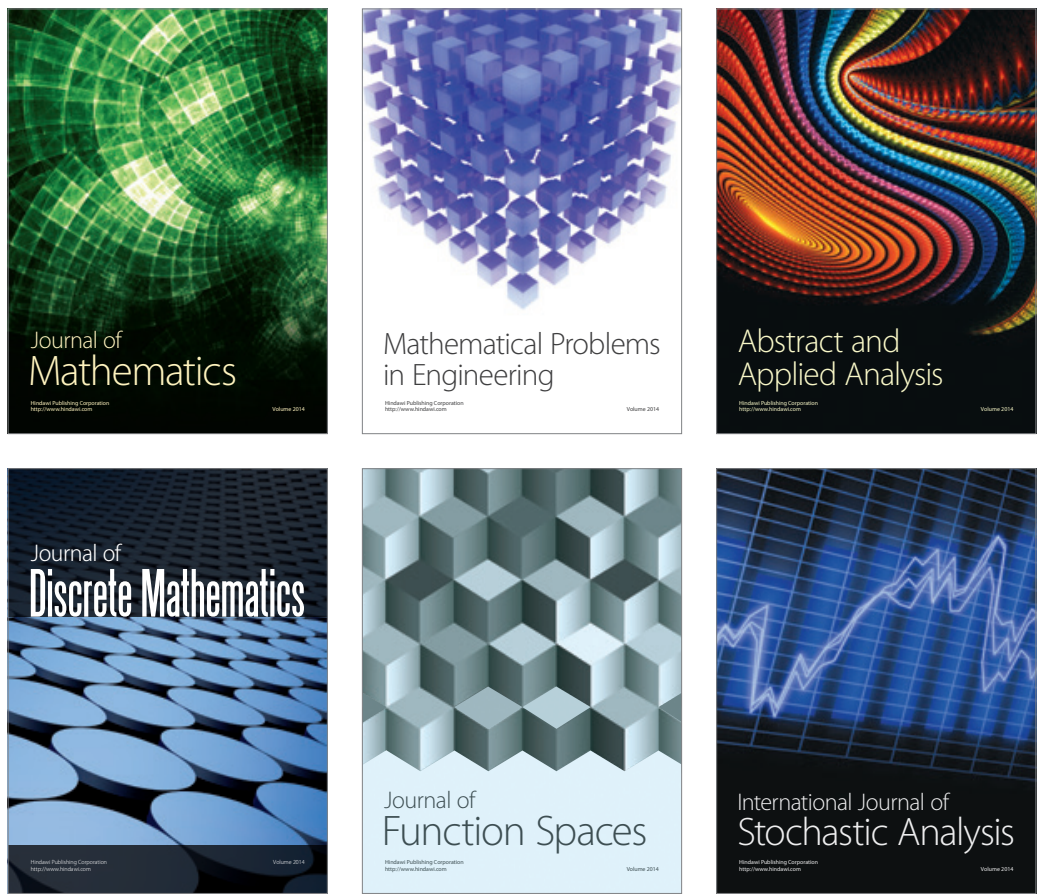

Journal of

Function Spaces

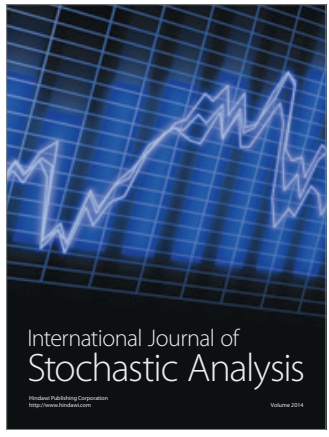

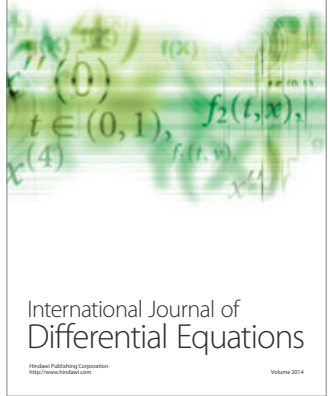
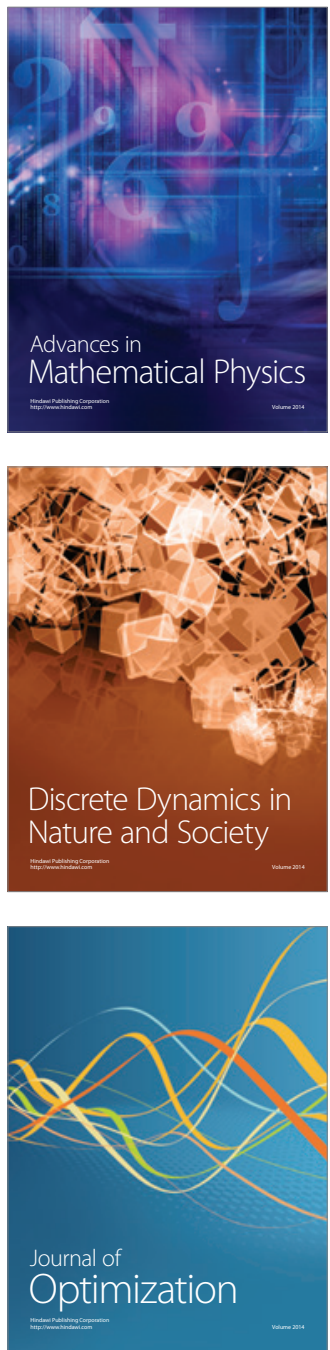